\title{
Choledochal Cyst-Current Management Strategies
}

\section{Dr. Shantanu Vyas ${ }^{1}$, Dr. Girish Chauhan ${ }^{2}$}

${ }^{1}$ Asst. Prof. Department of Surgery, SMS Medical College and Hospitals, Jaipur, Rajsathan, India

${ }^{2}$ Department of Surgery, SMS Medical College and Hospitals, Jaipur, Rajsathan, India dgoddard@angelo.edu

Abstract: Choledochal cysts in adults are often detected during the investigation of nonspecific symptoms. Choledochal cysts are uncommon and of unknown cause, with an incidence of $0.1 \%$ even among adults referred for endoscopic retrograde cholangiopancre atography (ERCP) investigation 2 . There is a higher incidence in females 3 , 4. The presentation is often vague and nonspecific, impending prompt diagnosis. However, the diagnosis is facilitated by modern imaging techniques. While some aspects of optimal management have been resolved, others remain controversial. Here in we report our experience concentrating particularly on current issues in management of the disease.

MRCP is the best imaging modality for diagnosis and characterization of these cysts. Complete excision and hepaticojejunostomy is the management of choice. Two drain (Subhiepatic and pelvis) should be put at time of surgery.

Keywords: Choledochal cysts, ERCP , hepaticojejunostomy

\section{INTRODUCTION}

Choledochal cysts are uncommon and of unknown cause, with an incidence of $0.1 \%$ even among adults referred for endoscopic retrograde cholangiopancre atography (ERCP) investigation 2. There is a higher incidence in females 3 , 4. The presentation is often vague and nonspecific, impending prompt diagnosis. However, the diagnosis is facilitated by modern imaging techniques. While some aspects of optimal management have been resolved, others remain controversial. Here in we report our experience concentrating particularly on current issues in management of the disease.

\section{Material ANd Methods}

Experience of 12 cases of Choledochal cyst- males 3, females 9, M:F 1:3, man age -21 years, Incidental with vague symptoms -6 , stones in choledochal cyst -2 , Cholangitis-4. All vague symptoms cases were initially diagnosis by USG out of which 2 were confirmed by ERCP and rest 4 by MRCP. Stones in choledochal cyst (2) suspected by USG and confirmed by ERCP. All four cholangitis presentation cases were suspected by USG and confirmed by MRCP (table 1). Complete excision of cyst was possible in 7 cases, while 3 cases upper cuff left for anastomosis and in two cases lower portion mucosa fulgurated and left in situ. No intraductal drain left, only drains in Morrison's pouch and pelvis left. 3 had minor leak with drain out put erris not more than 1 week, while 1 patient had a leak with drain out put varying from 400-600 ml daily during first 4 weeks and then 200$250 \mathrm{ml}$ daily during next 2 weeks and then on $49^{\text {th }}$ day no discharge in bag, Pelvic drain helped in all these 4 leak patients and waste removed from $7^{\text {th }}$ to $10^{\text {th }}$ day. 
Choledochal Cyst-Current Management Strategies

Table1

\begin{tabular}{|c|c|c|c|c|}
\hline S. no. & Presentation & No. of Cases & Initially Suspected & Diagnosis by \\
\hline 1 & Vague Symptoms & 2 & USG & ERCP \\
& & 4 & USG & MRCP \\
\hline 2 & Stone Choledochal cyst & 2 & USG & ERCP \\
\hline 3 & Cholangitis & 4 & USG & MRCP \\
\hline
\end{tabular}

DisCUSSION

Choledochal cysts are rare abnormalities of billary tree and so may be frequently overlooked in differential diagnosis. The no nspecific symptoms of choledochal cysts, including pain in upper abdomen and jaundice, are common in many other illnesses of upper gastrointestinal tract. The clinical triad of jaundice, right upper quadrant mass and abdominal pain occurs only in minority of patient's $(0 \%-17 \%)(3,5,6,7)$. It is more commonly seen in cases with onset in childhood rather than in adults, and $85 \%$ of children have at least 2 features of the triad at presentation, compared with only $25 \%$ of adults (8).

Among the more commonly reported presenting features are cholangitis, $(6,9,10)$ panereatitis, $(6,10,11,12)$ and billary peritonitis from cyst rupture $(6,13,14,15)$. Among adults, choledochal cysts are quite often incidental findings during investigation for other problems $(6,16,17,18)$. The most commonely used classification developed by Alonso-Lej et al (1959) ${ }^{19}$ and modified by Todani et al $(1977)^{20}$ describes 5 broad types of choledochal cysts. However, it is also not withant controversy. Some have argned that the term "Choledochal cyst" should refer to only type I and IV cysts (which comprise over $90 \%$ of biliary cysts) Vague abdominal pain is the prominent complaint in adults, which led all of our patients to seek medical attention, hence high index of suspicion should be observed in adult patients to have a prompt diagnosis. In adults, the diagnosis is only sporadically in doubt preoperatively, owing to the quality of modern imaging (1). Ultrasonography is usually the first examination and is very sensitive in the detection of cystic structures. A computed mography usually can give more information and modern techniques, including reconstruction, should allow for establishing the diagnosis. A better role for CT scanning may be in the postoperative period, where it was shown to be superior to MRCP in locating the billary enteric anastomosis and in defining any stenosis there of (1).

Endoscopic retrograde cholangiopanreatography (ERCP) although invasive can precisely visualize the extrahepatic bile duct (helped in confirming diagnosis in two patients presented with stone in cystic duct and rest 2 patients were from vague symptoms group prior to availability of MRCP). MRCP is currently the prefered reliable investigation as it also precisly by visualize complete biliary tree with advantage of being noninvasive MRCP helped in two third (8/12) of our cases.

Pancreatitis, cholangitis, Biliary cirrhosis and malignancy are the complication reported in choledochal cysts (1).

The treatment of choledochal cyst has changed. In the past, a cystojejunostomy was the standard procedure. Currently, Excision of the cyst and reconstruction by hepatieo jejunostomy is the standard therapy (1). The timing of surgery should be early after diagnosis to reduce the incidence of complications (22).

Postoperative anastomotic structure formation may be reduced by performing a higher anastomosis, as Todani (23) found that 9 of 22 choledochojunoiestomies had postoperative anastmotic strictures, compared with 1 of 82 hepaticojejunostomies.

Complete excision of cyst was possible in 58\% (7/12) ases, while 25\% (3/12) upper cuff of cyst was left for anastomosis with Jejunum as right and left hepatic ducts were $23 \mathrm{~mm}$ in diameter. In 16.6\% (2/12) cases lower part of cyst in pancreatic head area fulgerated and left in situ. 
$25 \%$ (3/12) cases had minor leak with drain out put persisting for 4-6 days. Pelvic drain helped in these leak cases as it drained in $1^{\text {st }}$ post operative week and removed on $7^{\text {th }}$ to $10^{\text {th }}$ day. One of our case had bile leak 400$600 \mathrm{ml}$ per day for almost a month and then 200-250 ml daily for next 2 weeks on $49^{\text {th }}$ day the drain stopped draining. This was probably because of small bile duct directly draining from liver into GB (Ducts of Luschka) unrecognized at time of surgery and hence not ligated.

\section{SUMMARY}

Choledochal cysts in adults are often detected during the investigation of nonspecific symptoms. MRCP is the best imaging modality for diagnosis and characterization of these cysts. Complete excision and hepaticojejunostomy is the management of choice. Two drain (Subhiepatic and pelvis) should be put at time of surgery.

\section{BIBLIOGRAPHY}

1. Matthew SM, Simon A WH, Guy JM. Management Dilemmas with choledochal cysts Arch. Surg 2003;138:333337.

2. SchmidtHG, BauerJ,WiessnerV,SchonekasH,Endoscopcaspects ofCholedochoceles. Hepatogastroenerology, 1996;43:143-146.

3. Watanatittan S, Niramis R, Choledochal cyst: review of 74 pediatrics cases, J Med Assoc Thai. 1998;586595.

4. Chen HM, Jan YY, Chen MF, et al. Surgical treatment of choledochal cyst in adults: results and long term follow-up. Hepatogastrology. 1996;43:1492-1499.

5. Stringer MD, Dhawan A, Davenporl M, Mieli-Vergani G, Mowat AP, Howard ER, Choleochal cyst. Lesion from a 20 years experience. Arch Dis Child. 1995;73:528-531.

6. Samuel M, Spitz L, Choledochal cyst: varied clinical presentation and long term results of surgery. Eur J Pediatric Surg: 1996;6:78:81

7. Rattan KN, Khurana P, Budhiraja S, Malik V, Pandit SK, Choledochal cyst a 10-years experience. Indian J Pediatr. 2000;67:657-659.

8. Lipsett PA, Pitt HA, Colonbani PM, Boitnott JK, Cameron JL. Choledochal Cyst disease: a changing pattern of presentation. Ann Surg. 1994;220:644-652.

9. Jan YY, Chen HM, Chen MF, Malignancy in choledochal cyst. Hepatogastro enterology. 2002;49:100-103.

10. Karanikas ID, Koundourakis SS, Macheras AN, Panagiotidis HC, Liakakos TD, Dendrinos SS, Long termresults of management of type I choledochal cysts in adults. Acta Chir Belg. 1997;97:13-18.

11. Lin JTH, Chen YH, Ni YH, Lai HS, Peng SS, Magnetic resonance cholangiopan creatography diagnosed pancreatitis associated choledochal cyst. Repost of one case. Acta Paediatric Taiwan 2001;42:363-366.

12. Weisser M, Bennek J, Hormann D, Choledochocele; a rare cause of necrotizing pancreatitis in children. Eur J Pediatr Surg. 2000;10:258-264.

13. Seema, Sharma A, Seith A, Taluja V, Bagga D, Aneja S, Spontaneous rupture of choledochal cyst. Indian J Pediatr. 2000;67:155-156.

14. Lin SL, Shan KM, Hung YB, Ng SH, Lin CY. Choledochal cyst associated with acute acalculous cholecystitis. J Pediatr Gastroenerol Nutr. 2000;31:307-308.

15. Ando K, Miyano T, Kohno S, Takamizawa S, Lane G. Spontaneous perforation of choledochal cyst a study of 13 cases. Eur J Pediatric Surg. 1998;8:23-25. 


\section{Choledochal Cyst-Current Management Strategies}

16. Sato M, Ishida H, Konno K, et al. Choledochal cyst due to anomalous pancreatobiliary junction in the adult sonographic findings. Abdom imaging. 2001;26:395-400.

17. Kim JE, Lee JK, Lee KT, et al. The clinical significate of common bile-duct dilatation in patients without biliary symptoms or causative lesions on ultrasonography. Endoscopy. 2001;33:495-500.

18. Liu DC, Rodriguez JA, Meric F, Geiger JL. Laparoscopic excision of a rare type II choledochal cyst case report and review of the literature. J Pediatr Surg. 2000;35:1117-1119.

19. Alonso-Lej F, Rever WBJ, Pessagno DJ. Congential choledochal cysts, with a report of 2, and an analysis of 94 cases. Surg Gynecol obstet. 1959;108:1-30.

20. Todani T, Watanabe Y, Narusue M, Tabuchi K, Okajima K. Congenital bile duct cysts: Classification, operative procedures, and review of twently seven cases including cancer orising from choledochal cyst. Am J Surg 1977;134:263-269.

21. Visser BC, Suh I, Way L Wetal. Congenital choledochal cysts in adult. Arch Surg 2004;139:855-860.

22. Lai HS, Duh YC, Chen WJ, et al. Manifestations and surgical treatment of choledochal cyst in different age group patients. J Formos Med Assoc. 1997;96:242-246.

23. Todani T, Watanabe $\mathrm{Y}$, Toki A, Ogura $\mathrm{K}$, Wang ZQ, Co-exiting biliary anomalies and anatomical variants in choledochal cyst. Br J Surg 1998;13:424-425.

Citation: Dr. Shantanu Vyas, Dr. Girish Chauhan, "Choledochal Cyst-Current Management Strategies". American Research Journal of Nursing. 2017; 3(1): 1-4.

Copyright (c) 2018 Dr. Shantanu Vyas, Dr. Girish Chauhan, This is an open access article distributed under the Creative Commons Attribution License, which permits unrestricted use, distribution, and reproduction in any medium, provided the original work is properly cited. 